\title{
A LONGITUDINAL STUDY OF ABNORMALITIES ON MRI AND DISABILITY FROM MULTIPLE SCLEROSIS
}

\author{
Peter A. Brex, M.D., Olga Ciccarelli, M.D., Jonathon I. O’Riordan, M.D., Michael Sailer, M.D., \\ Alan J. Thompson, M.D., ANd David H. Miller, M.D.
}

\begin{abstract}
Background In patients with isolated syndromes that are clinically suggestive of multiple sclerosis, such as optic neuritis or brain-stem or spinal cord syndromes, the presence of lesions as determined by $\mathrm{T}_{2}$-weighted magnetic resonance imaging (MRI) of the brain increases the likelihood that multiple sclerosis will develop. We sought to determine the relation between early lesion volume, changes in volume, and long-term disability.

Methods Seventy-one patients in a serial MRI study of patients with isolated syndromes were reassessed after a mean of 14.1 years. Disability was measured with the use of Kurtzke's Expanded Disability Status Scale (EDSS; possible range, 0 to 10, with a higher score indicating a greater degree of disability).

Results Clinically definite multiple sclerosis developed in 44 of the 50 patients (88 percent) with abnormal results on MRI at presentation and in 4 of 21 patients (19 percent) with normal results on MRI. The median EDSS score at follow-up for those with multiple sclerosis was 3.25 (range, 0 to 10); 31 percent had an EDSS score of 6 or more (including three patients whose deaths were due to multiple sclerosis). The EDSS score at 14 years correlated moderately with lesion volume on MRI at 5 years $(r=0.60)$ and with the increase in lesion volume over the first 5 years $(r=0.61)$.
\end{abstract}

Conclusions In patients who first present with isolated syndromes suggestive of multiple sclerosis, the increases in the volume of the lesions seen on magnetic resonance imaging of the brain in the first five years correlate with the degree of long-term disability from multiple sclerosis. This relation is only moderate, so the volume of the lesions alone may not be an adequate basis for decisions about the use of disease-modifying treatment. (N Engl J Med 2002; 346:158-64.)

Copyright $\odot 2002$ Massachusetts Medical Society.

I $\mathrm{N}$ patients who present with isolated syndromes that are clinically suggestive of multiple sclerosis, such as optic neuritis or brain-stem or spinal cord syndromes, multiple sclerosis can develop months or many years later. ${ }^{1,2}$ Ninety percent of patients with multiple sclerosis first present in this way. The presence of cerebral white-matter lesions as determined by $\mathrm{T}_{2}$-weighted magnetic resonance imaging
(MRI) at presentation (found in 50 to 70 percent of patients with isolated syndromes $)^{3-5}$ is associated with an increased risk of multiple sclerosis. ${ }^{6-9}$ Abnormalities on MRI have therefore been used to select patients with isolated syndromes for trials of disease-modifying therapies aimed at delaying the onset of multiple sclerosis. ${ }^{10,11}$

Little is known about the relation between early findings on MRI in patients with isolated syndromes and subsequent disability from multiple sclerosis. This presentation becomes important in the consideration of new early disease-modifying treatments and their potential to reduce long-term disability. ${ }^{12}$ In a previous report based on data from 10 years of follow-up, we found that a change in the number and volume of lesions correlated more strongly with a concurrent change in disability over the first 5 years than over the second 5 years. ${ }^{9,13}$ The number and volume of baseline lesions correlated moderately with the degree of disability $(\mathrm{r}=0.45)$ at year 10 . We have now followed the cohort for a mean of 14.1 years. The primary aim was to evaluate the strength of the relation between lesion volumes on earlier MRI scans and the degree of disability after 14 years.

\section{METHODS}

\section{Patients}

All the patients presented to the National Hospital at Queen Square or Moorfields Eye Hospital between 1984 and 1987. Isolated syndromes were presumed to be demyelinating central nervous system events reaching a peak within 14 days after the onset of symptoms in subjects 10 to 50 years of age with no history suggesting demyelination. Appropriate investigations were carried out to rule out alternative diagnoses.

Patients were initially recruited for clinical and MRI examinations at base line and after approximately one year; 109 patients were studied at both times. ${ }^{14,15}$ Further assessments took place after 5 years (89 patients) ${ }^{6}$ and 10 years ( 81 patients). ${ }^{9}$ The patients seen at 10 years were invited back for another clinical assessment and MRI examination. Progression to clinically definite or probable multiple sclerosis was defined with the use of the criteria of Poser at al., 16 solely on clinical grounds. Clinically definite cases were classified as relapsing-remitting or secondary progressive. ${ }^{17}$ Disability was measured with the use of the Kurtzke Expanded Disability Status Scale (EDSS; possible range, 0 to 10 , with a higher score indicating

From the Nuclear Magnetic Resonance Research Unit, Institute of Neurology, Queen Sq., London (P.A.B., O.C., A.J.T., D.H.M.); the Tayside Multiple Sclerosis Research Unit, Ninewells Hospital, Dundee, United Kingdom (J.I.O.); and Otto-von-Guericke Universität, Magdeburg, Germany (M.S.). Address reprint requests to Dr. Miller at the NMR Research Unit, Institute of Neurology, Queen Sq., London WCIN 3BG, United Kingdom.

158 - N Engl J Med, Vol. 346, No. 3 • January 17, $2002 \cdot$ www.nejm.org 
a greater degree of disability). ${ }^{18}$ For those who could not attend the examination, an EDSS score was obtained over the telephone with the use of a standard questionnaire; this approach was previously validated in a study of 110 patients, in which the intraclass correlation coefficient for the examination and telephone scores was 94.8 percent. ${ }^{19}$

\section{MRI}

MRI data were available for assessments at base line and at 5, 10, and 14 years but not for the 1-year follow-up examination. Imaging was performed on a 0.5 -T system (Picker, Cleveland) at base line and 5 years and on a 1.5-T scanner (General Electric Signa, Milwaukee) at 10 and 14 years. Contiguous, $\mathrm{T}_{2}$-weighted, axial slices of the brain were obtained at all visits. The slice thickness was $10 \mathrm{~mm}$ on 38 of the 71 base-line scans of patients who were followed up at 14 years and $5 \mathrm{~mm}$ on all other scans. The methods of counting lesions and quantifying lesion volume have been described previously.9,13

\section{Statistical Analysis}

Comparisons between groups were performed with the use of chi-square or Mann-Whitney tests as appropriate. The Spearman rank-correlation coefficient was used to evaluate the relation between the volumes and numbers of lesions on MRI during followup and the EDSS score after 14 years. Measures included the total volume or number of lesions at a given time point and changes in volume or number between two time points. The 95 percent confidence intervals of the $r$ value for each correlation between lesion volume and EDSS score were calculated as outlined by Altman. ${ }^{20}$ Similar confidence intervals were obtained with the use of the nonparametric bootstrap method. ${ }^{21}$ Selected pairs of correlation coefficients were compared with the use of a t-test-based method for comparing nonindependent correlations. ${ }^{22}$ The results of the rankcorrelation test were also calculated as $\mathrm{r}^{2}$, which provides a direct measure of the degree to which variability in the rank of the 14-year EDSS score is related to variability in the rank of each measure of volume on $\mathrm{T}_{2}$-weighted $\mathrm{MRI}$

\section{RESULTS}

Information was obtained on 72 of the 81 patients included in the 10-year follow-up; 8 could not be traced, and 1 declined to participate. One of the 72 patients was excluded since the symptoms were considered, in retrospect, to be due to cerebrovascular disease (the decision was made with knowledge of the MRI findings but was based on the clinical data). Of the remaining 71,3 had died from complications of severe multiple sclerosis by year 14 ( 1 between years 5 and 10 and 2 between years 10 and 14), 55 visited the hospital and underwent a neurologic and MRI examination, and 13 underwent EDSS assessment over the telephone.

The cohort of 71 included in the 14-year follow-up did not significantly differ from the original cohort of 109 in age at presentation, sex, type of syndrome, or frequency and volume of abnormalities on MRI at presentation (Table 1). The 68 surviving patients were assessed after a mean of 14.1 years (range, 12.5 to 16.8) when their mean age was 45 years (range, 33 to 64). Interferon beta had been prescribed after the 10year follow-up in only three patients; treatment was stopped after a brief period in two, and only one was continuing treatment at year 14 .

\section{Development of Multiple Sclerosis}

Clinically definite multiple sclerosis developed in 48 of 71 patients (68 percent) and probable multiple sclerosis in a further 5 ( 7 percent). The median EDSS score of patients with clinically definite multiple sclerosis was 3.25 (range, 0 to 10 ); 31 percent had an EDSS score of 6 or more (including three patients whose deaths were due to multiple sclerosis). Clinically definite multiple sclerosis developed in 25 of the 36 patients with optic neuritis (69 percent), 9 of the 14 patients with brain-stem syndromes (64 percent), and 14 of the 21 patients with spinal cord syndromes (67 percent).

\section{Normal MRI Scans at Base Line}

Clinically definite multiple sclerosis (all relapsingremitting) developed in 4 of 21 patients with normal MRI scans at base line (19 percent) with a median EDSS score of 1.75 (range, 1 to 2 ). The median time to the development of multiple sclerosis was 7.5 years (range, 5 to 11 ). Clinically probable multiple sclerosis developed in another patient. All five patients with new clinical events and three others (who were 39, 49, and 64 years of age) had new lesions on MRI. Thus, 8 of 21 patients (38 percent) exhibited clinical or imaging evidence of multiphasic disease.

\section{Abnormal MRI Scans at Base Line}

Clinically definite multiple sclerosis developed in 44 of 50 patients with abnormal MRI scans at base line (88 percent); 27 had relapsing-remitting disease (20 with an EDSS score of no more than 3 and 7 with an EDSS score greater than 3), and 17 had secondary progressive disease (including 3 who died from severe disease). The median EDSS score of these 44 patients was 3.5 (range, 0 to 10 ), and the median time to the development of multiple sclerosis was 2 years (range, 0.5 to 12 ). Clinically probable multiple sclerosis developed in four patients ( 8 percent). Of the two remaining patients, one had new lesions on MRI and the other declined follow-up imaging. Overall, 49 of 50 patients (98 percent) had clinical or radiologic evidence of multiphasic disease consistent with multiple sclerosis.

\section{Development of Disability}

Patients with worse clinical outcomes had larger numbers and volumes of lesions on MRI at base line (Table 2) and larger increases in lesion volume over time (Table 3). The median EDSS score at follow-up in those with more than 10 lesions at base line was 6 . All three patients who died as a result of multiple sclerosis had accumulated large volumes $(22,44.8$, and $76 \mathrm{~cm}^{3}$ ) at five years of follow-up.

The EDSS score at 14 years correlated moderately with the change in lesion volume on MRI over the 
Table 1. Characteristics of the Patients in the Mri Follow-up Studies.

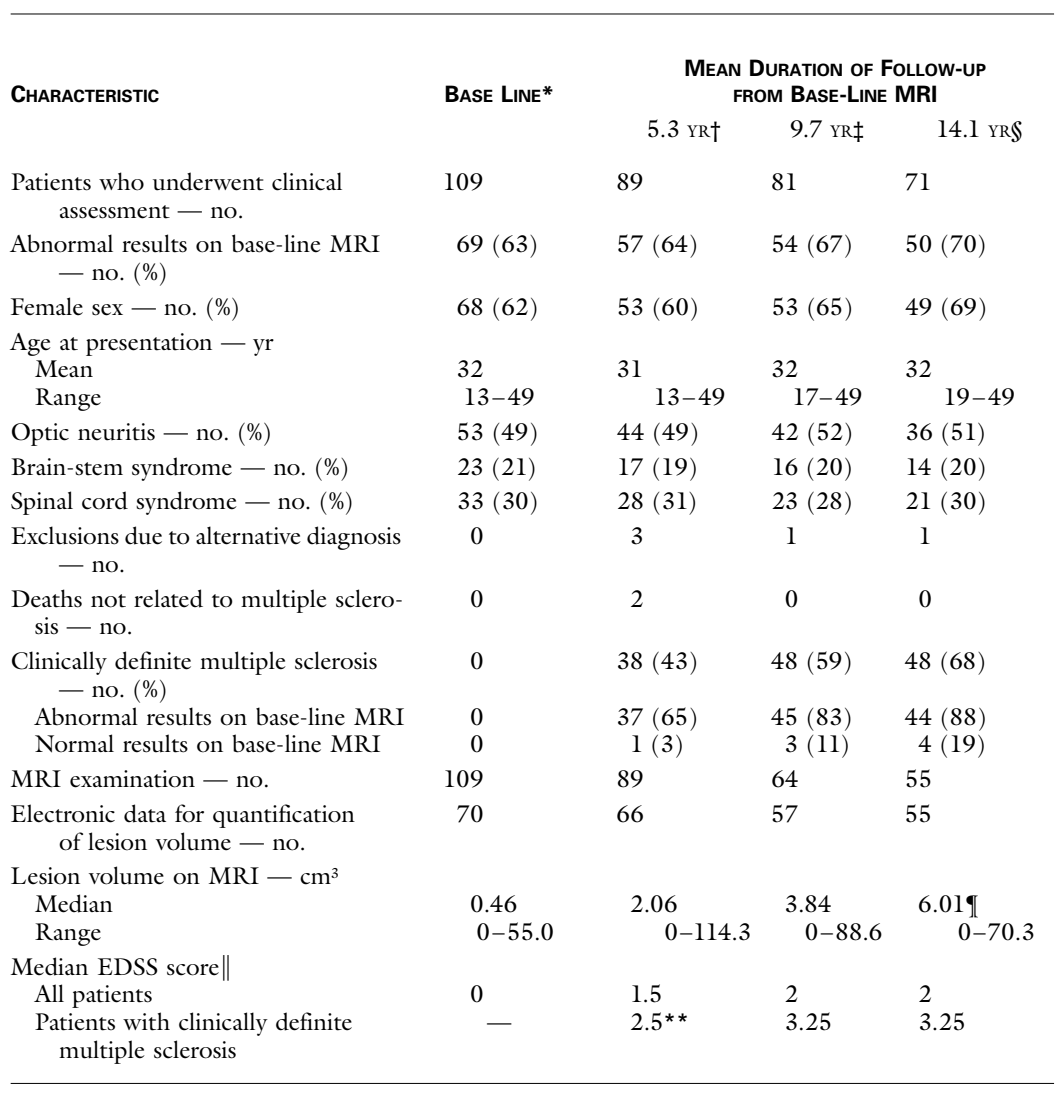

*Data are from Ormerod et al. ${ }^{3,4}$ and Miller et al. ${ }^{5,14,15}$

†Data are from Morrissey et al. ${ }^{6}$

$\ddagger$ Data are from O'Riordan et al. ${ }^{9}$

\$Data are from the present study.

IThe median lesion volume at presentation was $0.54 \mathrm{~cm}^{3}$ (range, 0 to 55.0 ).

||EDSS denotes Expanded Disability Status Scale (possible range, 0 to 10, with a higher score indicating a greater degree of disability).

**Data were missing for two patients.

first 5 years $(\mathrm{r}=0.61)$ and the lesion volume at 5 years $(\mathrm{r}=0.60)$ (Table 4$)$. Significant but weaker correlations were found between the EDSS score at 14 years and the earlier base-line volume $(\mathrm{r}=0.48)$ as well as later measures (lesion volume on MRI at 10 years, $\mathrm{r}=0.48$; change in volume from year 5 to year $10, r=0.29$; and change in volume from year 10 to year $14, \mathrm{r}=0.45$ ). Differences in the $r$ values were marginally significant for two of six pairwise comparisons: volumes at base line as compared with volumes at year 5 and changes in volume from year 0 to year 5 as compared with changes from year 5 to year 10 (Table 4 ).
The change in lesion volume on MRI correlated moderately with the change in the EDSS score over the first 5 years $(\mathrm{r}=0.58)$ and was weaker though still significant over the 5-to-10-year and 10-to-14-year periods (Table 5 ).

The EDSS score at 14 years was correlated with the number of lesions on MRI at base line $(r=0.47, \mathrm{P}<$ $0.001), 5$ years $(\mathrm{r}=0.55, \mathrm{P}<0.001)$, and 10 years $(\mathrm{r}=$ $0.45, \mathrm{P}=0.001)$ and with the number of new lesions on MRI from year 0 to year $5(\mathrm{r}=0.51, \mathrm{P}<0.001)$ and year 10 to year $14(\mathrm{r}=0.59, \mathrm{P}<0.001)$ but not from year 5 to year $10(\mathrm{r}=0.16, \mathrm{P}=0.25)$. 
Table 2. Number and Volume of Asymptomatic Lesions on $\mathrm{T}_{2}$-Weighted Mri of the Brain at Presentation in Patients with Isolated Syndromes, and Their Clinical Outcome after 14 Years.

Clinical Outcome

\begin{tabular}{lcclc}
$\begin{array}{l}\text { Isolated syndrome - no. (\%) } \\
\text { Clinically probable multiple } \\
\text { sclerosis - no. (\%) }\end{array}$ & $16(76)$ & $1(6)$ & 0 & $1(6)$ \\
$\begin{array}{l}\text { Clinically definite multiple } \\
\text { sclerosis - no. (\%) }\end{array}$ & $4(19)$ & $16(89)$ & $13(87)$ & $15(88)$ \\
EDSS score - no. & & & & \\
$>3$ & 0 & 5 & 7 & 12 \\
$\geqslant 6$ & 0 & 2 & 4 & 9 \\
10 & 0 & 0 & 1 & 2 \\
Median EDSS score & 1.75 & 2 & 4 & 6 \\
Range of EDSS scores & $1-2$ & $0-8$ & $0-10$ & $2-10$ \\
\hline
\end{tabular}

*The median volume was included when available.

\section{DISCUSSION}

Although case ascertainment was not complete, the patients in this 14-year follow-up cohort had similar clinical and imaging features at base line as the original cohort (Table 1) and are likely to be representative. Overall, 14 years after the first presentation, clinically definite multiple sclerosis had developed in 68 percent of the patients. This is in accordance with the prediction, based on actual follow-up for a mean of 11 years and life-table analysis, that multiple sclerosis would have developed in 75 percent of a cohort with optic neuritis after 15 years. ${ }^{23}$ Prospective studies of similar length in other countries have reported lower frequencies in patients with isolated optic neuritis, with multiple sclerosis developing in 38 to 58 percent of patients after 13 to 15 years of follow-up., ${ }^{1,2}$ Multiple sclerosis developed in a similar proportion with brain-stem or spinal cord syndromes, and inclusion of these cases does not account for the difference. The higher conversion rate in our cohort may reflect geographic variations in the course of the disease, or a higher proportion of patients in whom multiple sclerosis did not develop may have been lost to follow-up. However, we know of four patients who had multiple sclerosis when seen at 10 years and who were lost to follow-up at 14 years.

Of those with abnormalities on MRI at base line, 98 percent exhibited either clinical or radiologic evidence of multiphasic disease; this long-term follow-up study therefore confirms that white-matter lesions on MRI in young adults with isolated syndromes are, in almost all instances, due to multiple sclerosis. Indeed,
Table 3. Lesion Volumes at Each Time Point, According to Clinical Outcome after 14 Years.

\begin{tabular}{|c|c|c|c|c|}
\hline Clinical Outcome & BASE LINE & 5 YeARS & 10 YeARS & 14 YeARS \\
\hline \multicolumn{5}{|l|}{ Died (EDSS score of 10) } \\
\hline Median volume $\left(\mathrm{cm}^{3}\right)$ & 9.9 & 44.8 & 88.6 & - \\
\hline Range $\left(\mathrm{cm}^{3}\right)$ & $1.2-10.5$ & $22-76$ & - & - \\
\hline No. of patients & 3 & 3 & 1 & - \\
\hline \multicolumn{5}{|l|}{$\begin{array}{l}\text { Secondary progressive } \\
\text { multiple sclerosis }\end{array}$} \\
\hline Median volume $\left(\mathrm{cm}^{3}\right)$ & 2.5 & 16.8 & 21.3 & 28.1 \\
\hline Range $\left(\mathrm{cm}^{3}\right)$ & $0.2-55$ & $1.3-114$ & $1.1-46$ & $0.5-70$ \\
\hline No. of patients & 12 & 11 & 7 & 9 \\
\hline \multicolumn{5}{|l|}{$\begin{array}{l}\text { Relapsing-remitting } \\
\text { multiple sclerosis } \\
(\text { EDSS score }>3 \text { ) }\end{array}$} \\
\hline Median volume $\left(\mathrm{cm}^{3}\right)$ & 2.4 & 5.7 & 15.6 & 21.6 \\
\hline Range $\left(\mathrm{cm}^{3}\right)$ & $0.5-6.1$ & $3.3-21.7$ & $6.3-39$ & $16.6-52$ \\
\hline No. of patients & 5 & 5 & 5 & 5 \\
\hline \multicolumn{5}{|l|}{$\begin{array}{l}\text { Relapsing-remitting } \\
\text { multiple sclerosis } \\
\text { (EDSS score } \leqslant 3 \text { ) }\end{array}$} \\
\hline Median volume $\left(\mathrm{cm}^{3}\right)$ & 0.6 & 2 & 5.9 & 8.0 \\
\hline Range $\left(\mathrm{cm}^{3}\right)$ & $0-13.7$ & $0-36.6$ & $0.6-37$ & $1-37.9$ \\
\hline No. of patients & 22 & 22 & 21 & 22 \\
\hline \multicolumn{5}{|l|}{$\begin{array}{l}\text { Clinically probable } \\
\text { multiple sclerosis }\end{array}$} \\
\hline Median volume $\left(\mathrm{cm}^{3}\right)$ & 1.0 & 3.5 & 3.8 & 5.0 \\
\hline Range $\left(\mathrm{cm}^{3}\right)$ & $0-2.6$ & $1.4-10.9$ & $2.0-16.3$ & $4.2-15.1$ \\
\hline No. of patients & 5 & 5 & 5 & 5 \\
\hline \multicolumn{5}{|l|}{ Isolated syndrome } \\
\hline Median volume $\left(\mathrm{cm}^{3}\right)$ & 0 & 0 & 0 & 0 \\
\hline Range $\left(\mathrm{cm}^{3}\right)$ & $0-0.4$ & $0-0.6$ & $0-0.6$ & $0-5.5$ \\
\hline No. of patients & 16 & 13 & 13 & 13 \\
\hline
\end{tabular}

new diagnostic criteria for multiple sclerosis, based on serial MRI findings, have recently been promulgated for patients with clinically isolated syndromes. ${ }^{24}$ In contrast, prolonged follow-up of those with normal scans confirms the good prognosis already observed during short-term follow-up studies: clinically probable or definite multiple sclerosis had developed in only one fifth of patients, and none had become disabled. A significant proportion of this subgroup may nevertheless have multiple sclerosis, albeit a mild form, since almost 40 percent had new lesions on follow-up MRI. Although one patient was at an age (64 years) when new lesions due to incidental vascular disease are common, the findings suggest that more prolonged follow-up is warranted. Some patients have had a second episode after 30 or more years.

The average degree of disability of patients was mild, though the wide range included all levels of the EDSS scale. Whereas the median EDSS score of patients with clinically definite multiple sclerosis was 3.25 , other natural-history studies have found that after 15 years, 50 percent will require aid to walk (equivalent to an EDSS score of 6). ${ }^{25-27}$ There are several possible explanations for the difference. First, the largest subgroup had op- 


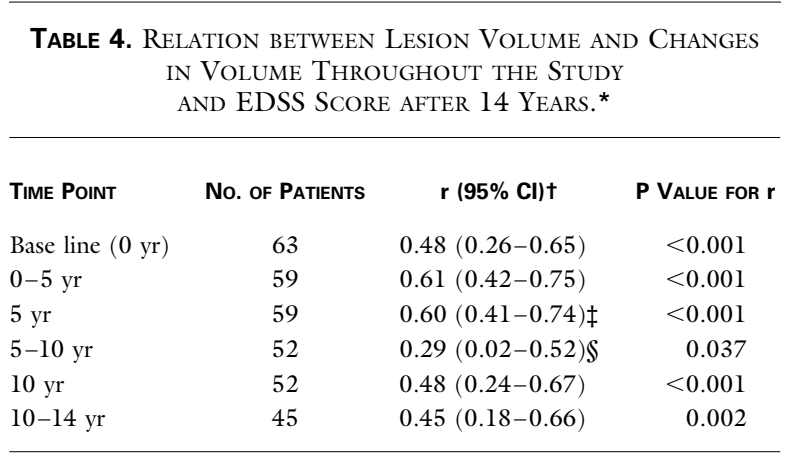

* Other pairwise comparisons of $\mathrm{r}$ values for absolute volumes (base line vs. 10 years, $\mathrm{P}=0.5 ; 5$ years vs. 10 years, $\mathrm{P}=0.43$ ) and changes in volume $(0$ to 5 years vs. 10 to 14 years, $\mathrm{P}=0.89 ; 5$ to 10 years vs. 10 to 14 years, $\mathrm{P}=0.29$ ) were not significant.

$\dagger$ The $\mathrm{r}$ denotes the Spearman rank-correlation coefficient, and CI confidence interval.

$\ddagger \mathrm{P}=0.056$ for the comparison with base line according to the t-testbased method for comparing nonindependent correlations.

$\S \mathrm{P}=0.064$ for the comparison with 0 to 5 years according to the t-testbased method for comparing nonindependent correlations.

tic neuritis, which may have a milder disease course; 70 to 80 percent have minimal disability after followup periods of 8 to 15 years. ${ }^{1,28}$ Second, all patients were followed prospectively whether multiple sclerosis developed or not, with assessment at regular intervals $(1,5,10$, and 14 years after onset); this helped detect cases of multiple sclerosis in patients in whom relapses were mild and disability was minimal. Third, patients with primary progressive multiple sclerosis were not included in the present study but have been in other studies ${ }^{27,29}$; disability develops more rapidly in this subgroup than in those with relapse. ${ }^{29}$

The EDSS score at 14 years correlated significantly with lesion volumes on MRI at all of the earlier time points, indicating that the lesion volume at any time contributes to the development of later disability. Lesion numbers show broadly similar correlations but are less reliable than volumes as a measure of disease progression, because lesion sizes vary and enlargement and the confluence of lesions are not accounted for. The volume on MRI after 5 years and the change in volume during the first 5 years correlated more strongly with the EDSS score at 14 years than did measures of volume at earlier or later time points, suggesting that the development of lesions in the early years has an important influence on long-term disability.

Natural-history studies have identified a relation between clinical features during the early years and long-term disability. The frequency of relapse and the interval between relapses during the first 2 years, ${ }^{26}$ incomplete recovery from relapses during the first 5 years, ${ }^{27}$ and the degree of disability after 5 years ${ }^{30}$
Table 5. Correlation between Change in Lesion Volume ON MRI AND CHANGe IN EDSS SCORE FOR ALL Available Patients.*

\begin{tabular}{|c|c|c|c|}
\hline VARIABLE & $0-5$ Years & 5-10 YeARS & $10-14$ YeARS \\
\hline No. of patients & 66 & 57 & 45 \\
\hline \multicolumn{4}{|c|}{ Change in EDSS score } \\
\hline Median & 1.5 & 0.5 & 0 \\
\hline Range & 0 to 8.5 & -1 to 5 & -1.5 to 6 \\
\hline \multicolumn{4}{|c|}{$\begin{array}{l}\text { Change in lesion volume } \\
\left(\mathrm{cm}^{3}\right)\end{array}$} \\
\hline Median & 1.11 & 0.85 & 0.83 \\
\hline Range & -0.4 to 65.9 & -0.34 to 67.0 & -4.0 to 13.6 \\
\hline \multicolumn{4}{|c|}{$\begin{array}{l}\text { Correlation between change } \\
\text { in EDSS score and } \\
\text { change in volume }\end{array}$} \\
\hline $\mathrm{r}$ & 0.58 & 0.41 & 0.35 \\
\hline$P$ value & $<0.001$ & 0.002 & 0.02 \\
\hline
\end{tabular}

*EDSS denotes the Expanded Disability Status Scale, and $r$ the Spearman rank-correlation coefficient.

have been associated with the development of disability up to 25 years later. The apparent influence of relapses at this early stage contrasts with the situation in patients who have entered the progressive phase of multiple sclerosis, in whom relapses no longer influence progressive disability. ${ }^{29}$ The present MRI study and previous clinical studies suggest that both MRI and clinical measures of disease activity in the first two to five years after the development of an isolated syndrome are important in the long-term prognosis for disability in patients with multiple sclerosis.

Lesions on MRI correspond to demyelinating plaques at autopsy, ${ }^{31}$ and most new lesions develop from a focal region of breakdown of the blood-brain barrier $^{32}$ associated with active inflammation and demyelination..$^{33} \mathrm{~A}$ large lesion volume in the early years implies that extensive inflammation and demyelination have already occurred. On the other hand, a likely mechanism of progressive disability is axonal loss, which can be extensive in chronic lesions. ${ }^{34}$ Putative magnetic resonance markers of axonal loss (e.g., tissue atrophy or reduced $\mathrm{N}$-acetyl aspartate on magnetic resonance spectroscopy) indicate that axonal loss is more abundant in disabled patients with a progressive course. ${ }^{35,36}$

The extent of inflammation and demyelination early in the disease course may influence the extent of later axonal loss in several ways. First, acute inflammation is associated with axonal damage, including transection $^{37,38}$; widespread axonal loss will diminish the amount of axonal reserve, and a threshold may be reached at an early point when continuing axonal loss

162 • N Engl J Med, Vol. 346, No. 3 • January 17, 2002 • www.nejm.org 
- by whatever mechanism - begins to manifest as disability. Second, widespread inflammation could expose a range of potential autoantigens to immune surveillance, resulting in complex immunopathogenic events due to epitope spreading ${ }^{39}$; such a process may be less regulated and may be likely to cause axonal damage. Third, widespread early demyelination itself may create an environment that is not conducive to long-term axonal survival.

Pathologic features other than the total volume of the lesions are likely to contribute to disability: these include axonal loss in lesions, abnormalities in the normal-appearing tissues, diffuse atrophy, and spinal cord disease. Magnetic resonance techniques such as $\mathrm{T}_{1}$-weighted imaging (for hypointense and contrastenhancing lesions), magnetic resonance spectroscopy, magnetization-transfer imaging, and diffusion tensor imaging are more pathologically specific than $\mathrm{T}_{2}$-weighted MRI and should be incorporated into future studies.

This study provides MRI data over many years. Although there was a change in scanner and slice thickness during the study, this had little influence ${ }^{40,41}$ on the large increases seen in the lesion volumes, which included an increase in the median volume by a factor of 11 over a 14 -year period. Furthermore, none of these patients were treated with disease-modifying drugs during the first 10 years; three patients received interferon beta after year 10. Now that agents that substantially modify lesion volume on MRI are being widely used in patients with relapsing-remitting multiple sclerosis, ${ }^{42}$ it is unlikely that similar data from long-term natural-history studies on the development of lesions on MRI will be obtained.

The study demonstrates that lesion volume on MRI in patients with isolated syndromes and early multiple sclerosis (the first five years of the disease) is of prognostic value in assessing the risk of future disability. The correlations are only moderate, which cautions against the use of lesion volume alone to decide about the use of disease-modifying treatments for individual patients. Although the results suggest a potential longterm clinical benefit of therapies that suppress lesion formation in the early years of disease, the mechanisms underlying the observed relation between clinical and MRI data are uncertain, and prospective long-term follow-up of cohorts receiving disease-modifying treatments will be needed to clarify this issue.

Supported by a program grant from the Multiple Sclerosis Society of Great Britain and Northern Ireland, by Schering, by the International Federation of Multiple Sclerosis Societies, and by the University of Rome La Sapienza.

We are indebted to Prof. W.I. McDonald, Dr. I.F. Moseley, Dr. D.P.E. Kingsley, Dr. K. Miszkiel, Dr. S. Morrissey, and Mr. D.G. MacManus for their contributions and to Dr. M. King for statistical advice and analysis.

\section{REFERENCES}

1. Rizzo JF III, Lessell S. Risk of developing multiple sclerosis after uncomplicated optic neuritis: a long-term prospective study. Neurology 1988; 38:185-90.

2. Sandberg-Wollheim M, Bynke $H$, Cronqvist $S$, Holtas S, Platz P, Ryder LP. A long-term prospective study of optic neuritis: evaluation of risk fac tors. Ann Neurol 1990;27:386-93.

3. Ormerod IE, McDonald WI, du Boulay GH, et al. Disseminated lesions at presentation in patients with optic neuritis. J Neurol Neurosurg Psychiatry 1986;49:124-7.

4. Ormerod IE, Bronstein A, Rudge $P$, et al. Magnetic resonance imaging in clinically isolated lesions of the brain stem. J Neurol Neurosurg Psychiatry 1986;49:737-43.

5. Miller DH, McDonald WI, Blumhardt LD, et al. Magnetic resonance imaging in isolated noncompressive spinal cord syndromes. Ann Neurol 1987;22:714-23.

6. Morrissey SP, Miller DH, Kendall BE, et al. The significance of brain magnetic resonance imaging abnormalities at presentation with clinically isolated syndromes suggestive of multiple sclerosis: a 5-year follow-up study. Brain 1993;116:135-46.

7. Optic Neuritis Study Group. The 5 -year risk of MS after optic neuritis: experience of the Optic Neuritis Treatment Trial. Neurology 1997;49: 1404-13.

8. Barkhof F, Filippi M, Miller DH, et al. Comparison of MRI criteria at first presentation to predict conversion to clinically definite multiple sclerosis. Brain 1997;120:2059-69.

9. O'Riordan JI, Thompson AJ, Kingsley DP, et al. The prognostic value of brain MRI in clinically isolated syndromes of the CNS: a 10-year followup. Brain 1998;121:495-503.

10. Comi G, Filippi M, Barkhof F, et al. Effect of early interferon treatment on conversion to definite multiple sclerosis: a randomised study. Lan cet $2001 ; 357: 1576-82$.

11. Jacobs $\mathrm{LD}$, Beck RW, Simon $\mathrm{JH}$, et al. Intramuscular interferon betala therapy initiated during a first demyelinating event in multiple sclerosis. N Engl J Med 2000;343:898-904.

12. Noseworthy JH, Lucchinetti C, Rodriguez M, Weinshenker BG. Multiple sclerosis. N Engl J Med 2000;343:938-52.

13. Sailer M, O'Riordan JI, Thompson AJ, et al. Quantitative MRI in patients with clinically isolated syndromes suggestive of demyelination. Neurology 1999;52:599-606.

14. Miller DH, Ormerod IE, McDonald WI, et al. The early risk of multiple sclerosis after optic neuritis. J Neurol Neurosurg Psychiatry 1988;51: 1569-71.

15. Miller DH, Ormerod IE, Rudge P, Kendall BE, Moseley IF, McDonald WI. The early risk of multiple sclerosis following isolated acute syndromes of the brainstem and spinal cord. Ann Neurol 1989;26:635-9.

16. Poser CM, Paty DW, Scheinberg L, et al. New diagnostic criteria for multiple sclerosis: guidelines for research protocols. Ann Neurol 1983;13: 227-31.

17. Lublin FD, Reingold SC. Defining the clinical course of multiple sclerosis: results of an international survey. Neurology 1996;46:907-11.

18. Kurtzke JF. Rating neurologic impairment in multiple sclerosis: an Expanded Disability Status Scale (EDSS). Neurology 1983;33:1444-52.

19. Lechner-Scott J, Kappos L, Hofman M, et al. Can the Expanded Disability Status Scale (EDSS) be assessed by phone? Mult Scler (in press).

20. Altman DG. Practical statistics for medical research. London: Chapman \& Hall, 1991:293-5.

21. Efron $B$, Tibshirani RJ. An introduction to the bootstrap. New York: Chapman \& Hall, 1993.

22. Steiger JH. Tests for comparing elements of a correlation matrix. Psychol Bull 1980;87:245-51.

23. Francis DA, Compston DA, Batchelor JR, McDonald WI. A reassessment of the risk of multiple sclerosis developing in patients with optic neuritis after extended follow-up. J Neurol Neurosurg Psychiatry 1987;50:75865.

24. McDonald WI, Compston A, Edan G, et al. Recommended diagnostic criteria for multiple sclerosis: guidelines from the International Panel on the diagnosis of multiple sclerosis. Ann Neurol 2001;50:121-7.

25. Confavreux C, Aimard G, Devic M. Course and prognosis of multiple sclerosis assessed by the computerized data processing of 349 patients. Brain 1980;103:281-300.

26. Weinshenker BG, Bass B, Rice GP, et al. The natural history of multiple sclerosis: a geographically based study. 2 . Predictive value of the early clinical course. Brain 1989;112:1419-28.

27. Runmarker B, Andersen O. Prognostic factors in a multiple sclerosis in cidence cohort with twenty-five years of follow-up. Brain 1993;116:117-34. 
28. Ghezzi A, Martinelli V, Torri V, et al. Long-term follow-up of isolated optic neuritis: the risk of developing multiple sclerosis, its outcome, and the prognostic role of paraclinical tests. J Neurol 1999;246:770-5.

29. Confavreux C, Vukusic S, Moreau T, Adeleine P. Relapses and progression of disability in multiple sclerosis. N Engl J Med 2000;343:1430-8.

30. Kurtzke JF, Beebe GW, Nagler B, Kurland LT, Auth TL. Studies on the natural history of multiple sclerosis. 8. Early prognostic features of the later course of the illness. J Chronic Dis 1977;30:819-30.

31. Stewart WA, Hall LD, Berry K, Paty DW. Correlation between NMR scan and brain slice data in multiple sclerosis. Lancet 1984;2:412.

32. Miller DH, Rudge $P$, Johnson $G$, et al. Serial gadolinium enhanced magnetic resonance imaging in multiple sclerosis. Brain 1988;111:927-39. 33. Katz D, Taubenberger JK, Cannella B, McFarlin DE, Raine CS, McFarland HF. Correlation between magnetic resonance imaging findings and lesion development in chronic, active multiple sclerosis. Ann Neurol 1993; 34:661-9.

34. Lassmann H, Suchanek G, Ozawa K. Histopathology and the bloodcerebrospinal fluid barrier in multiple sclerosis. Ann Neurol 1994;36: Suppl:S42-S46.

35. Losseff NA, Webb SL, O'Riordan JI, et al. Spinal cord atrophy and disability in multiple sclerosis: a new reproducible and sensitive MRI method with potential to monitor disease progression. Brain 1996;119:701-8.

36. Fu L, Matthews PM, De Stefano N, et al. Imaging axonal damage of normal-appearing white matter in multiple sclerosis. Brain 1998;121:103 13.

37. Ferguson B, Matyszak MK, Esiri MM, Perry VH. Axonal damage in acute multiple sclerosis lesions. Brain 1997;120:393-9.

38. Trapp BD, Peterson J, Ransohoff RM, Rudick R, Mörk S, Bö L. Axonal transection in the lesions of multiple sclerosis. N Engl J Med 1998; 338:278-85.

39. Katz-Levy Y, Neville KL, Padilla J, et al. Temporal development of autoreactive Thl responses and endogenous presentation of self myelin epitopes by central nervous system-resident APCs in Theiler's virus-infected mice. J Immunol 2000;165:5304-14.

40. Molyneux PD, Tubridy N, Parker GJ, et al. The effect of section thickness on MR lesion detection and quantification in multiple sclerosis. AJNR Am J Neuroradiol 1998;19:1715-20.

41. Filippi $M$, van Waesberghe $J H$, Horsfield $M A$, et al. Interscanner variation in brain MRI lesion load measurements in MS: implications for clinical trials. Neurology 1997;49:371-7.

42. Paty DW, Li DK. Interferon beta-lb is effective in relapsing-remitting multiple sclerosis. II. MRI analysis results of a multicenter, randomized, double-blind, placebo-controlled trial. Neurology 1993;43:6627.

Copyright (C) 2002 Massachusetts Medical Society.

POSTING PRESENTATIONS AT MEDICAL MEETINGS ON THE INTERNET

Posting an audio recording of an oral presentation at a medical meeting on the Internet, with selected slides from the presentation, will not be considered prior publication. This will allow students and physicians who are unable to attend the meeting to hear the presentation and view the slides. If there are any questions about this policy, authors should feel free to call the Journal's Editorial Offices.

164 • N Engl J Med, Vol. 346, No. 3 • January 17, $2002 \cdot$ www.nejm.org 